\title{
Prospective field emitters for miniature high voltage electronic devices operating at technical vacuum conditions
}

\author{
G.G. Sominskii, V.E. Sezonov, E.P.Taradaev, T.A. Tumareva
}

Peter the Great Saint Petersburg Polytechnic University, St. Petersburg, Russia, sominski@rphf.spbstu.ru

The use of field emitters is promising for the creation of systems for formation of electron flows in many electronic devices, since they do not require heating and are inertialess. Until recently, the field emitters were used mainly in ultra-high vacuum, low current and low voltage devices. Meanwhile, miniature, but high voltage electronic devices, which it is difficult to use with thermionic cathodes, are attracting more and more interest. Such are, for example, electron-beam microwave devices of short millimeter and sub-millimeter wavelengths, as well as miniature X-ray sources, operating at accelerating voltages of units - tens $\mathrm{kV}$. Emission currents of several tens milliamps at current densities of the order of or more than $100-150 \mathrm{~mA} / \mathrm{cm}^{2}$, are required, as a rule in these applications. Not only the difficulty of sufficiently high currents producing by field emitters, but also their low durability impedes their use in high voltage devices. Basic mechanisms of cathodes destruction are associated with an intense bombardment of their surface by residual gas ions typical for such devices, with the impact of ponderomotive forces, large in strong electric fields, and/or by the thermal effects at the selection of the large emission currents. Using distributed systems as field emitters allows to facilitate the current load on the single emission center, minimize the effect of ponderomotive forces and thermal effects. However usually, ion bombardment restricts the use of field emitters in high-voltage electronic devices.

Multi-tip silicon field emitters (MSE) with new type double-layer metal - fullerene coating were developed and investigated in the laboratory of "High current and microwave electronics" of SPbPU $[1,2]$. The main investigations were performed for structures of silicon tips with a height $h=30 \mu \mathrm{m}$ and tip top radius $R=5-10 \mathrm{~nm}$. The distance $L$ between the tips was set equal to their height. With this relation $L$ and $h$, there was a partial mutual shielding of the tips [3, 4], which reduced the magnitude of the electric field at their top. However, in the investigated sufficiently high-voltage modes in a diode system with the cathode-anode distance of $1.5 \mathrm{~mm}$ at voltages of $5-15 \mathrm{kV}$, it was possible to create electric fields at the surface of the tips of the order of (4-6) $110^{7} \mathrm{~V} / \mathrm{cm}$, which were necessary for intense field emission.

The layer of molybdenum with thickness from 5 to $20 \mathrm{~nm}$ deposited on the surface of a multi-tip silicon structure increased its conductivity and strength. A thin (from 2 to 10 monolayers) film of fullerene $\mathrm{C}_{60}$ molecules was deposited on the molybdenum layer to protect cathode against the destructive effect of ion bombardment. Calculations performed using SRIM program [5] showed that such a thin fullerene film is transparent enough for ions of sufficiently high energy (over $1000 \mathrm{eV}$ ). Such fast bombarding cathode ions lose less than $1 \%$ of their ener- gy in the film and dissipate the most part of their energy in the molybdenum substrate. On the other hand, for slow molybdenum atoms "knocked out" of the substrate, the thin fullerene coating is practically not transparent. As a result, the created thin fullerene coating minimize ion sputtering of multi-tip cathodes.

The fullerene coating increases the work function of the surface of the tips to approximately $5.3 \mathrm{eV}$. However, treating a multi-tip cathode with a slow $(40 \mathrm{eV})$ flow of potassium ions makes it possible to reduce the work function of the tip structure surface by $15-20 \%$ due to the formation of stable metallo-fullerenes such as endo$\left(\mathrm{C}_{60} @ \mathrm{~K}\right)$ and / or exohedrals $\left(\mathrm{K} @ \mathrm{C}_{60}\right)$ in a coating.

The operation of cathodes with activated and nonactivated coatings was investigated. It was showed, that used activated and non-activated coatings protect emitters from the destructive action of the ion bombardment at energies of bombarding cathode ions up to $15 \mathrm{keV}$. MSE with area of $0.2-0.3 \mathrm{~cm}^{2}$ with not activated coating provides the field emission currents of up to about $100 \mathrm{~mA}$ at emission current densities up to approximately $0.4-1.0$ $\mathrm{A} / \mathrm{cm}^{2}$. The maximal currents of activated cathodes of the approximately same area were smaller and did not exceed 40-50 mA. In our opinion, this is due to the fact that when the coating is activated, some of the potassium atoms that is not captured by the fullerene molecules, intercallate under the fullerene coating and reduce its bond with the substrate.

The created multi-tip emitters are able to provide stable field emission necessary for the functioning of diagnostic gyrotrons of short-wave millimeter and submillimeter wavelengths. At present, the concept of creating diagnostic gyrotrons with an operating frequency about $260 \mathrm{GHz}$ with cold multi-tip cathodes has been developed [6] in cooperation with the Institute of Applied Physics RAS. The use of created multi-tip cathodes in portable X-ray sources is also promising [7], as we think.

Along with the investigation of mentioned multi-tip emitters, the possibility of using developed by the authors original multi-layer cathodes in the high-voltage electronic devices is studied in SPbPU [1, 8]. For obtainment of field emission, the fields near the contacts of nano-layers of materials with different work function are used. Performed calculations and experiments have shown that the field emission of the layered cathodes depends on the thickness $\Delta$ of the contacted layers, on the difference in the work functions $\Delta e \varphi$ of these layers, and on the number $N$ of pairs of layers. The obtained data indicate that the thickness of the layers with a larger work function should be approximately equal to $2 \mathrm{~nm}$. The optimum thickness of the layers with smaller work function should be approximately $10-15 \mathrm{~nm}$. The cathodes including 10 
20 pairs of ytterbium-carbon layers $(\Delta e \varphi \sim 1.6 \mathrm{eV})$ and cathodes from the same number of pairs of hafniumplatinum layers $(\Delta e \varphi \sim 1.8 \mathrm{eV})$ were studied in the most detail. The largest field emission currents and current densities were obtained for Hf-Pt cathodes including 20 pairs of layers. Currently, a stable field emission of 2-3 milliamps at average current densities along the surface up to about $200 \mathrm{~A} / \mathrm{cm}^{2}$ was obtained with the cathodes of this type. We hope that there is the fundamental possibility to obtain higher emission currents from the layered cathodes with larger emitting area.

This work was funded by the grant of the Russian Science Foundation №16-12-10010.

\section{References}

1. Sominski, G.G., Sezonov, V.E., Taradaev, E.P., Tumareva, T.A., Zadiranov, Y.M., Kornishin, S.Y., Stepanova, A. N. Innovative Field Emitters for High-Voltage Electronic Devices // Radiophysics and Quantum Electronics. 2015.V. 58.No.7. P.511-519.
2. Sominskii, G.G., Tumareva, T.A., Taradaev, E.P., Mishin, M.V., \& Stepanova, A.N. Multitip semiconductor field emitters with new-type bilayer protecting coatings // Technical Physics. 2015. V.60. No. 1.P.133-136.

3. Eletskii, A.V. Carbon nanotube-based electron field emitters // Physics-Uspekhi, 2010. V.53. No. 9. P. 863.

4. Sominski, G.G., Taradaev, E.P., Influence of Surface Morphology on The Characteristics of Multi-Tip Field Emitters with Two-Layer Metal - Fullerene Coatings // Proc. of 11th Int. Vacuum Electron Sources Conference. Oktober 18-20. 2016. Seoul, Korea.P.67-68.

5. Ziegler, James F. Srim-2003 // Nuclear Instruments and Methods in Physics Research Section B: Beam Interactions with Materials and Atoms. 2004. V. 219-220. P. $1027-1036$.

6. Glyavin, M.Y., Manuilov, V.N., Sominskii, G.G., Taradaev, E.P., Tumareva, T.A. The concept of an electron-optical system with field emitter for a spectroscopic gyrotron. // Infrared Physics \& Technology. 2016. V. 78. P. 185-189.

7. Zhang, M., Naik, R.R., Dai, L. (Eds.). Carbon Nanomaterials for Biomedical Applications. V. 5. 2015. Springer.

8. Sominski, G.G., Sezonov, V.E., Tumareva, T.A, Taradaev, E.P. Field Emitter // RF Patent №118119. Published 10.07.2012. 